\title{
Spectrum of Lesions in Peritumoral Area in Association with Carcinoma of Breast
}

\author{
Shushan S Jayker ${ }^{1}$, Sahithi Tadi ${ }^{2}$, Jyothi R Kaluva ${ }^{3}$, Sharmila P Surhonne ${ }^{4}$
}

\begin{abstract}
Introduction: Breast cancer remains a global health problem with an increasing incidence. Breast carcinogenesis emerges by a multistep process via steps of hyperplasia, premalignant change, and in situ carcinoma. Women with proliferative breast disease have been observed to have an increased risk of breast cancer. Improved knowledge of breast carcinogenesis will provide insight for defining the high-risk groups, thus resulting in improved screening and management regimens.

Materials and methods: The present study included 60 radical mastectomies for carcinoma of breast at RajaRajeswari Medical College and Hospital, Bengaluru, from August 2015 to July 2018. The primary tumor and peritumoral area were studied both grossly and microscopically for the different lesions and the results were analyzed.

Observation and results: Of the 60 cases of breast carcinomas, the predominant type of carcinoma was infiltrating ductal carcinoma, no specific type (88\%) (IDC, NOS). The lesions in peritumoral area were fibrocystic changes (62\%), proliferative breast lesions (13\%), and ductal carcinoma in situ (DCIS) (25\%).

Conclusion: Most of the peritumoral area showed fibrocystic changes which have a less absolute risk of $3 \%$, whereas DCIS has an absolute lifetime risk of 25-30\% transforming into carcinoma of breast, making those patients mandatory for follow-up and management.

Keywords: Breast cancer, Peritumoral area, Proliferative breast disease.

The Journal of Medical Sciences (2019): 10.5005/jp-journals-10045-00130
\end{abstract}

\section{INTRODUCTION}

Breast cancer remains a global health problem with an increasing incidence. ${ }^{1}$ Breast carcinogenesis emerges by a multistep process via steps of hyperplasia, premalignant change, and in situ carcinoma. ${ }^{2}$ Benign breast diseases encompasses a spectrum of histologic entities usually subdivided into nonproliferative breast lesions, proliferative breast lesions without atypia, and proliferative breast lesions with atypia. ${ }^{3}$ Nonproliferative changes do not increase the risk of cancer. Proliferative breast disease is associated with a mild increased risk, while proliferative disease (PD) with atypia confers a moderate increase in the risk of breast cancer. ${ }^{4}$ Improved knowledge of breast carcinogenesis will provide insight for defining the highrisk groups, thus resulting in improved screening and management regimens.

\section{Materials and Methods}

A total 60 cases of radical mastectomy specimens for carcinoma of breast received in the Department of Pathology over a period of 3 years at RajaRajeswari Medical College and Hospital, Bengaluru, were included in the study. The specimens were grossed according to the standard protocol. The primary tumor and peritumoral area were assessed and additional bits were taken from the peritumoral area. The tissue bits were processed routinely and sections were stained by hematoxylin and eosin stain for microscopic examination. Data regarding age, categorization of lesions, and its percentage were analyzed.

\section{Results}

Of the 60 cases, 56 cases were infiltrating ductal carcinoma (IDC), no otherwise specified (NOS) type, 1 case each of lobular carcinoma, mixed lobular and ductal carcinoma, mucinous carcinoma, and
${ }^{1-4}$ Department of Pathology, RajaRajeswari Medical College and Hospital, Bengaluru, Karnataka, India

Corresponding Author: Shushan S Jayker, Department of Pathology, RajaRajeswari Medical College and Hospital, Bengaluru, Karnataka, India, Phone: +91 9844795849, e-mail: shwetajayker@gmail.com

How to cite this article: Jayker SS, Tadi S, Kaluva JR, et al. Spectrum of Lesions in Peritumoral Area in Association with Carcinoma of Breast. J Med Sci 2019;5(3):63-66.

Source of support: Nil

Conflict of interest: None

intracystic papillary carcinoma was diagnosed. The peritumoral area of these cases showed a single lesion or a combination

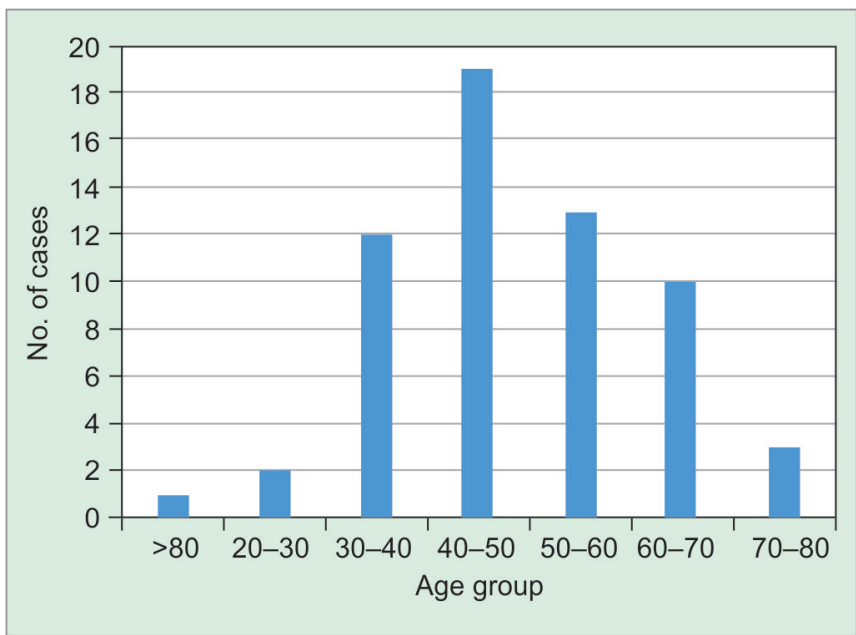

Fig. 1: Age distribution

() The Author(s). 2019 Open Access This article is distributed under the terms of the Creative Commons Attribution 4.0 International License (https://creativecommons. org/licenses/by-nc/4.0/), which permits unrestricted use, distribution, and non-commercial reproduction in any medium, provided you give appropriate credit to the original author(s) and the source, provide a link to the Creative Commons license, and indicate if changes were made. The Creative Commons Public Domain Dedication waiver (http://creativecommons.org/publicdomain/zero/1.0/) applies to the data made available in this article, unless otherwise stated. 


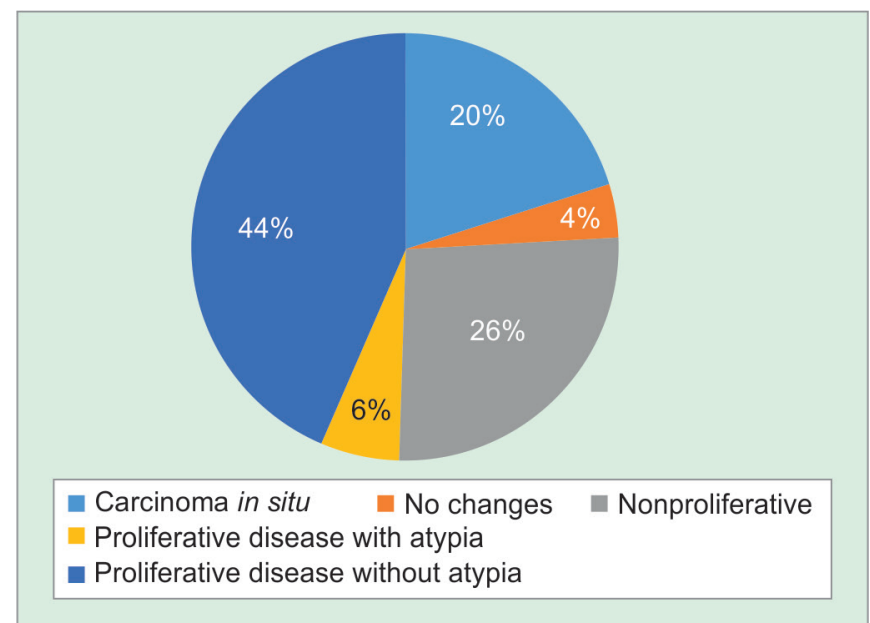

Fig. 2: Adjacent tissue changes in carcinoma breast

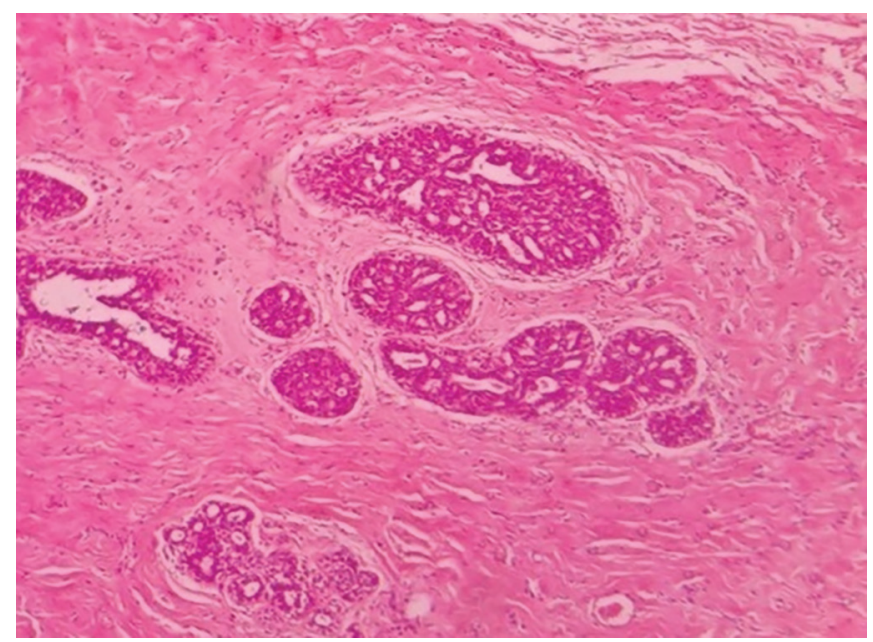

Fig. 4: Microphotograph showing florid epithelial hyperplasia (H\&E 10X)

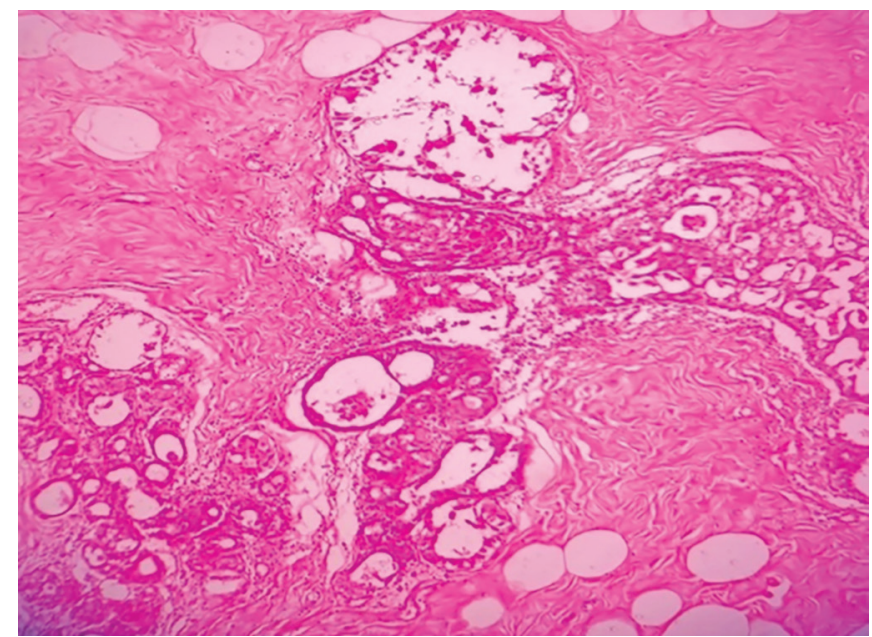

Fig. 6: Microphotograph showing cribriform ductal carcinoma in situ (DCIS) (H\&E 10X)

of lesions. Age of the patients ranged from 21 to 80 years. Most of cases were seen in the age-group of 41-60 years (Fig. 1). Most common findings were of proliferative epithelial lesions without atypia (44\%) noted in the adjacent tissue of carcinoma breast (Fig. 2).

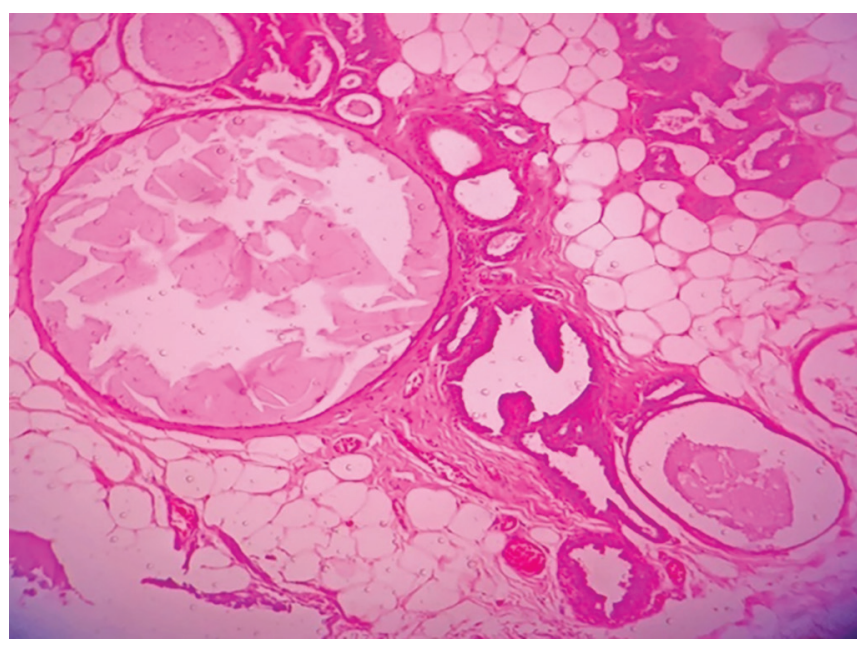

Fig. 3: Microphotograph showing fibrocystic change with apocrine metaplasia (H\&E 10X)

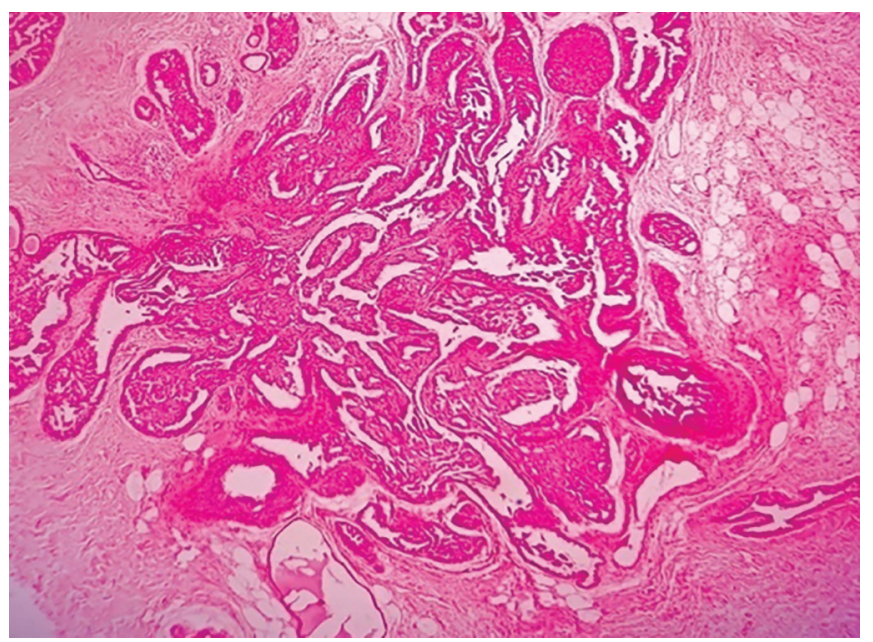

Fig. 5: Microphotograph showing papillomatosis within duct (H\&E 10X)

The different lesions noted in the peritumoral area in our study were fibrocystic change (33\%) (Fig. 3), adenosis (10\%), apocrine metaplasia (9\%), sclerosing adenosis (1\%), usual ductal hyperplasia (6\%), moderate ductal hyperplasia (2\%), florid ductal hyperplasia (2\%) (Fig. 4), atypical ductal hyperplasia (2\%), micropapillary hyperplasia (2\%), intraductal papilloma (3\%) (Fig. 5), and DCIS (20\%) (Figs 6 and 7). No changes were observed in the remaining four cases (4\%) (Table 1).

\section{Discussion}

Benign breast disease is an important risk factor for a later breast cancer, which can develop in either breast. ${ }^{1}$ It encompasses a spectrum of histologic entities, usually subdivided into nonproliferative lesions, proliferative lesions without atypia, and atypical hyperplasias (AHs), with an increased risk of breast cancer associated with proliferative or atypical lesions. ${ }^{2-5}$ Dupont and Page found that women with non-PD did not have an increased risk of a later breast cancer. ${ }^{2}$ They observed a prevalence of $\mathrm{AH}$, proliferative disease without atypia (PWDA), and non-PD of $4 \%, 27 \%$, and $69 \%$, respectively. Their reported prevalence of $\mathrm{AH}$ and PWDA is somewhat lower than that reported here. ${ }^{6}$ 


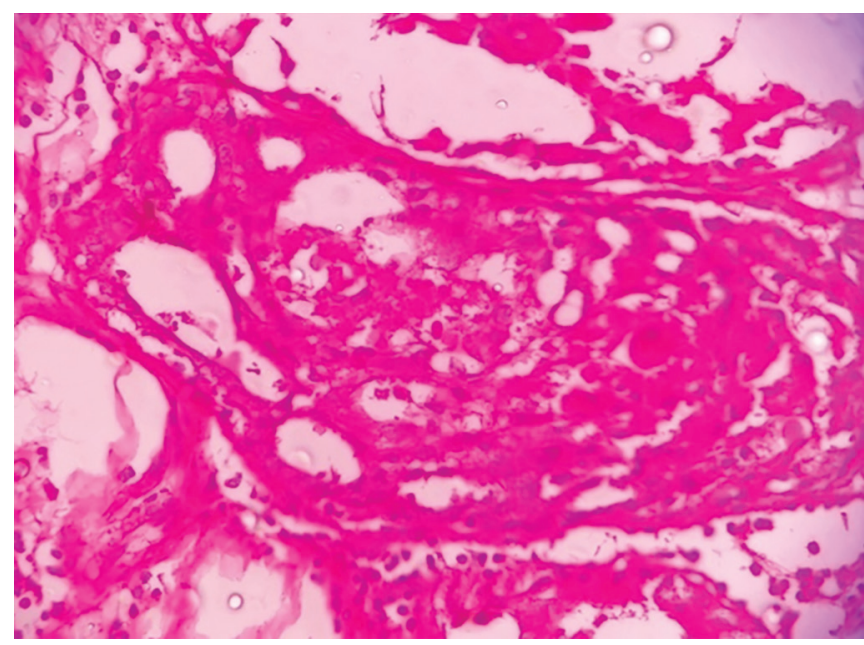

Fig. 7: High-power view of cribriform DCIS (H\&E 40X)

Table 1: Associated changes in adjacent tissues of carcinoma breast

\begin{tabular}{lcc}
\hline Type of lesion & Number & Percentage \\
\hline Adenosis & 10 & 10 \\
Apocrine metaplasia & 9 & 9 \\
Papillary apocrine metaplasia & 1 & 1 \\
Duct ectasia & 5 & 5 \\
Fibrocystic change & 33 & 33 \\
Duct papilloma & 3 & 3 \\
Sclerosing adenosis & 2 & 2 \\
Usual ductal hyperplasia & 6 & 6 \\
Florid ductal hyperplasia & 2 & 2 \\
Micropapillary hyperplasia & 2 & 2 \\
Atypical ductal hyperplasia & 2 & 2 \\
DCIS & 20 & 20 \\
No changes & 4 & 4 \\
Total lesions & 100 & \\
\hline
\end{tabular}

Table 2: Comparison of lesions with other studies

\begin{tabular}{|c|c|c|c|c|}
\hline & $\begin{array}{l}\text { Nonprolifer- } \\
\text { ative lesions } \\
\text { (\%) }\end{array}$ & $\begin{array}{l}\text { Proliferative } \\
\text { lesions } \\
\text { without } \\
\text { atypia (\%) }\end{array}$ & $\begin{array}{l}\text { Proliferative } \\
\text { lesions with } \\
\text { atypia (\%) }\end{array}$ & $\begin{array}{l}\text { Other } \\
\text { changes } \\
(\%)\end{array}$ \\
\hline Present study & 26 & 44 & 6 & 24 \\
\hline Shashikala et al. ${ }^{8}$ & 27 & 20 & 18 & 35 \\
\hline $\begin{array}{l}\text { Bhagyalakshmi } \\
\text { et al. }^{9}\end{array}$ & 16 & 29 & 10 & 45 \\
\hline London et al. ${ }^{5}$ & 38 & 39.6 & 22.3 & \\
\hline Hartmann et al. ${ }^{10}$ & 66.6 & 29.6 & 3.6 & \\
\hline
\end{tabular}

Table 3: Comparison of age-group with other studies

\begin{tabular}{lll}
\hline & Age group & Percentage \\
\hline Present study & $30-50$ & 51 \\
Shashikala et al. $^{8}$ & $31-50$ & 59 \\
Bhagyalakshmi et al. $^{9}$ & $30-50$ & 51 \\
\hline
\end{tabular}

Most of the peritumoral area in our study showed proliferative lesions (50\%), of which $44 \%$ were without atypia and $6 \%$ with atypia. The nonproliferative lesions accounted for $26 \%$, DCIS in $20 \%$ of cases and $2 \%$ of cases had no changes (Fig. 2). The results in our study were in concordance with other studies (Table 2).

Palli et al. ${ }^{7}$ performed a case-control study nested in a cohort of approximately 6,000 women in the Florence district of Italy, who underwent benign breast biopsies. They found that breast cancer risks in women with PDWA and $\mathrm{AH}$ relative to those without PD were 1.3 (95\% confidence interval $(\mathrm{Cl}), 0.5-3.5)$ and $13(95 \% \mathrm{Cl}$, 4.1-42), respectively.

The age range in our study of 60 cases was $20-80$ years and $30-50$ years was the most common age-group for breast carcinomas. This is similar to the studies done by Shashikala et al. ${ }^{8}$ and Bhagyalakshmi et al. (Table 3). ${ }^{9}$ The predominant histological subtype of carcinoma diagnosed was IDC, NOS type (88\%).

The presence of atypia in women under 45 years of age conveyed twice the risk observed among women over 55 years of age (6.99 and 3.37, respectively), which might relate, in part, to menopausal status. ${ }^{10}$

However, in the National Surgical Adjuvant Breast and Bowel Project (NSABP) study of women with lower categories of benign breast disease, the risk of breast cancer was greatest among postmenopausal women. ${ }^{11}$

Two main types of carcinoma-in-situ (CIS) are describedDCIS and lobular carcinoma in situ. Previous studies of CIS indicate that approximately a third will subsequently develop invasive carcinoma (IC). Autopsy studies indicate that CIS is frequently occurring and it was estimated that about $20 \%$ of all women will develop CIS during lifetime. Only a minor fraction is ever diagnosed, though the incidence of DCIS is increasing, especially related to mammography screening. ${ }^{12}$

\section{Conclusion}

Breast carcinomas are increasing in incidence, with $51 \%$ of cases seen in $<50$ years of age in the present study. Proliferative epithelial lesions are at increased risk of subsequent breast cancer. We noted the frequency of these lesions associated with breast carcinoma in $50 \%$ of cases. Hence, diagnosis of these lesions has gained momentum in recent years. With careful follow-up with clinical breast examination every 6 to 12 months and annual mammographic screening can reduce the occurrence of invasive breast cancer.

\section{References}

1. Lap P, Tan KL, Chen B. Correlation of HER-2 status with estrogen and progesterone receptors and histologic features in 3,655 invasive breast carcinomas. Am J Clin Pathol 2005;123(4):541-546. DOI: 10.1309/YMJ3A83TB39MRUT9.

2. Rosen J. Chapter 10. Precancerous Breast Disease: Epidemiological, Pathological and Clinical consideration. Rosen's Breast Pathology Rosen PP, ed. 3rd ed. Lippincott Williams and Wilkins; 2009. pp. 264-284.

3. Schnitt SJ. Benign breast disease and breast cancer risk: morphology and beyond. Am J Surg Pathol 2003;27(6):836-841. DOI: 10.1097/00000478-200306000-00017.

4. Dupont WD, Parl FF, Hartmann WH, et al. Breast cancer risk associated with proliferative breast disease and atypical hyperplasia. Cancer 1993;71(4):1258-1265. DOI: 10.1002/ 1097-0142(19930215)71:4<1258::AID-CNCR2820710415>3.0.CO;2-I.

5. London SJ, Connolly JL, Schnitt SJ, et al. A prospective study of benign breast disease and the risk of breast cancer. JAMA 1992;267(7): 941-944. DOI: 10.1001/jama.1992.03480070057030.

6. Dupont WD, Page DL. Risk factors for breast cancer in women with proliferative breast disease. N Engl J Med 1985;312(3):146-151. DOI: 10.1056/NEJM198501173120303. 
7. Palli $D$, Rosselli del Turco $M$, Simoncini R, et al. Benign breast disease and breast cancer: a case-control study in a cohort in Italy. Int J Cancer 1991;47(5):703-706. DOI: 10.1002/ijc.2910470513.

8. Shashikala R, Ravindra S. Proliferative fibrocystic lesions in association with carcinoma breast-Study of mastectomy specimens. Int J Biomed Adv Res 2015;6(8):574-579. DOI: 10.7439/ijbr.v6i8.2304.

9. Rema Nair S, Himaja S, Bhagyalakshmi A. Prospective study of histological proliferative changes in adjacent areas of breast cancer. J Evid Based Med Healthc 2016;3(90):4881-4885.
10. Hartmann $\mathrm{CL}$, Sellers AT, Frost HM, et al. Benign Breast Disease and the Risk of Breast Cancer. N Engl J Med 2005;353(3):229-237. DOI: 10.1056/NEJMoa044383.

11. Wang J, Costantino JP, Tan-Chiu E, et al. Lower category benign breast disease and the risk of invasive breast cancer. J Natl Cancer Inst 2004;96(8):616-620. DOI: 10.1093/jnci/djhs105.

12. Ottesen GL. Carcinoma in situ of the female breast. A clinicopathological, immunohistological, and DNA ploidy study. APIMS Suppl 2003(108):1-67. 